\title{
HR Practices and Employee Performance Relationship in Higher Education: Mediating Role of Job Embeddedness, Perceived Organizational Support and Trust
}

\author{
Mehreen Fatima \\ Department of Management Sciences \\ COMSATS Institute of Information Technology, Lahore, Pakistan \\ mehrinf@gmail.com \\ Muhammad Shafique \\ University of Engineering \& Technology (UET), Lahore, Pakistan \\ shafiqkarim@gmail.com \\ Faisal Qadeer \\ Lahore Business School, University of Lahore, Pakistan \\ faisal.qadeer@lbs.uol.edu.pk \\ Rashid Ahmad \\ COMSATS Institute of Information Technology, Lahore, Pakistan \\ rakhan@ciitlahore.edu.pk
}

\begin{abstract}
The purpose of this paper is to find out the impact of Human Resource practices on employee performance. Job embeddedness, Perceived organizational support and Trust were taken as mediators and they were investigated for their mediation effect on the relationship between human resource practices and employee performance. Organizational citizenship behavior and task performance were taken as two dimensions of Employee Performance. Data was collected through questionnaires from faculty members of seven campuses of a Public sector University in Pakistan. Results support that job embeddedness, perceived organization support and trust have partial or full mediation role for Human Resource PracticesPerformance relationship of teaching faculty of Higher Education sector.
\end{abstract}

Keywords: Job Embeddedness, Organizational Citizenship Behavior, Task Performance, Perceived Organizational Support, Trust.

\section{Introduction}

Organizational climate is defined by many researchers as the shared perception of employees about their work environment (Schneider 2000, Kuenzi and Schminke 2009). Hartel (2008) identified that one of the indicators of the existence of positive work environment in an organization is "employees' perceptions of the workplace environment as positive, respectful, inclusive and psychologically safe; leaders and co-workers as trustworthy, fair and diversity open; and policies and decision making as interactionally, procedurally and distributively just".

Many empirical studies have used human resource practices and managerial practices as predictors of service climate (Schneider et al. 1998). In our study, instead of taking conventional human resource practices like recruitment, training, performance appraisal, compensation etc. rather we adopted those HR practices which are perceived by the 
employees as organizational resources that facilitate their work. Demerouti et al. (2001) defined organizational resources as those organizational facets attached or available for a job which are not only helpful in reaching work targets but also instigate individual growth and development. Job characteristics theory acknowledged that resources have the potential to motivate employees (Hackman and Oldham 1980). Schaufeli and Bakker (2004) had explained that job resources act as precursor for motivational process. Therefore, job resources available in an organization fuel personal growth of employee and augment motivation. In this paper, organizational resources are dealt with as "facilitators" for employees in workplace as they appear to have this potential that motivates employees to give better performance. It is suggested by researchers that HR practices like training (Wayne et al. 1997) and autonomy (Eisenberger et al. 1999) increases perceived organizational support which in turn increase job performance of employees (Rhoades and Eisenberger 2002). Perceived organizational support has its foundations in norm of reciprocity (Gouldner 1960) and social exchange theory (Blau 1964).

Mitchell et al. (2001) introduced job embeddedness as a new construct and argued that it influences the decisions of employees regarding intension to stay in or leave the organization. They described it as a net which encompass an individual and he gets stuck. Afterwards, findings of some other research studies also depicted that job embeddedness is a valuable predictor of employee retention or intention to leave the job (Holtom and O' Neill 2004, Cunningham et al. 2005, Shafique et al. 2011). Mitchell et al. (2001) developed job embeddedness consisting of three dimensions: (1) links to other people, teams, and groups, (2) self-perception of employees of their fit with job, organization, and community; and (3) self-perception of employees of the sacrifice connected with quitting the job.

The higher the employees are motivated and experience personal growth, the more they feel embedded in their job. Bergiel et al. (2009) reported in their study that there exists a negative relationship between employees' intention to quit and human resource practices; and this relationship is mediated by job embeddedness. It could be safely said that HR practices (organizational resources) have the potential to increases job embeddedness and they are perceived by the employees as facilitating factors.

Trust in the place of work has been increasingly acknowledged as a critical feature that play vital role in boosting performance of the organization (Gould-Williams 2003). Bennis and Nanus (1985) described trust as a "lubrication that makes it possible for organizations to work". Trust of the workplace acts as a source of amplified effectiveness and efficiency (Culbert and McDonough 1986) and employees choose to work with the employer who promotes trust (Pascale and Athos 1981, Hage 1980). As trust seems to be linked with sought-after organizational outcomes therefore creating organizational environment where trust sustains will lead to a "win-win" state of affairs. Luhmann (1979) proposed trust as a dichotomous variable which comprise of two components namely interpersonal and systems trust. Interpersonal trust comprise of relationship among employees, while systems trust is supposed to consist of trust between employee and the organization. Luhmann (1979) argued that systems trust is more constant and durable in comparison to interpersonal trust that accepts very low or no influence by routine workplace activities. 
Human resource practices are found to have positive impact on employee performance. In this study, our taxonomy of employee performance consisted of two dimension i.e. task performance and organizational citizen behavior. Motowildo et al. (1997) mentioned task and contextual performance as the underlying dimensions of job performance in their "theory of individual differences in task and contextual performance". They stated that task performance has direct link to the technical core of an organization as it executes organizational technical processes and maintain its technical requirements. On the other hand, contextual performance does not contribute towards technical procedures but it comprises of activities (i.e. facilitating and assisting others; volunteering to perform activities which are not formal part of the job; practicing organizational policy and regulations even when they are not convenient) which enhance and preserve social and psychological climate in the organization which is necessary for the technical process to function properly. Organizational citizenship behavior is taken as contextual performance in this study as it is envisaged as analogous to contextual performance in literature (Organ 1997). Organ (1988) defined organizational citizenship behavior as "individual behavior that is discretionary, not directly or explicitly recognized by the formal reward system, and that in the aggregate promotes the effective functioning of the organization". Therefore, this study focuses on three areas of human resource practices (organizational resources), namely training, autonomy and technology. These three human resource practices have been used in this study to find out their impact on employee performance and where job embeddedness, perceived organizational support and trust act as mediators.

\section{Research Objective}

This study had two specific purposes.

- First, we sought to extend theory and research on job embeddedness by displaying how it predicts the decision to perform (organizational citizenship behavior and task performance).

- Second, this study is to identify whether job embeddedness, perceived organizational support and trust mediates the relationship between independent variable, i.e. human resource practices, and dependent variables, i.e. organizational citizenship behavior and task performance.

\section{Literature review}

Shaw et al. (1998) consider that training, to employees, works as an investment strategy for job permanence. Mitchell et al. (2001) stress that if job embeddedness construct is in play, training should increase the fit between the employee and job; and employee should experience high sacrifice if he chooses to leave the organization. Human resource practices of an organization are a gesture which indicates to the employees how much they are trusted (Guzzo and Noonan 1994, Iles et al. 1990). It is argued that trust acts as a mediating variable between HR practices and employee attitude (Guest and Conway, 1999).

Trust is found to be a critical factor in realizing sought-after worker performance. It has always been associated with improved social dealings and relations between workers 
(Gibb 1964). Culbert and McDonough (1986) explained that if an employee perceives that his organization does not considers him trustworthy and does not identify and remunerate for his contribution it will compel him to give only tabulated performance. Such behavior of employees will discourage him to show any activity related to organizational citizenship behavior. Lack of trust induces low commitment in employees which leads to innumerable cost due to little usage of personal potential (Diffie-Couch 1984). Social exchange makes a component of employment agreement (Rousseau 1989) and trust is the spirit of social exchange (Robinson et al., 1994). This exchange increases with the increase in trust development. Gould-Williams (2003) conducted a study on public sector in UK to find out the impact that HR practices cast on workplace trust and organizational performance. He concluded that HR practices have great influence over trust and organizational performance.

Bergiel et al. (2009) reported in his study that better HR practices are associated with low intension to quit the job and this relationship is mediated by job embeddedness. Autonomy is employees' perception about the control that they have for carrying out their job. Offering autonomy to employees in carrying out their work will eventually increase their employees' perceived organizational support (Eisenberger et al. 1999). Wayne et al. (1997) stated that training is useful for the employee and so it increases their perceived organizational support. Training not only augments performance of the employee related to their task but also initiates employees to involve in actions that go ahead of allocated responsibilities and are constructive for the organization.

Those employees with high job embeddedness are linked to their job, fit well with their work and think they will have to sacrifice many cherished things if they choose to leave the job. Sekiguchi et al. (2008) stated that these elements of job embeddedness are expected to impact employee performance positively. Moreover, "anti-withdrawal" mechanism of job embeddedness also instigates employees to perform (Lee et al. 2004). That means, those employees who are highly embedded in their job, will show comparatively higher organization citizenship behavior and task performance as compared to those who are less embedded. Consistent with this concept, on-the-job embeddedness is found to be predictor of organization citizenship behavior and employee task performance (Lee et al. 2004).

Organ (1988) suggested that organizational citizenship behavior is related both to the performance of individual and organization. Organ (1997) and Van Dyne et al. (1995) take task performance and organization citizenship behavior as in-role and extra-role performance behaviors respectively. They emphasized that these performance behaviors lead to the efficacy of the organization. Many other researchers also reported that organizational citizenship behavior has positive relationship with organization performance (Podsakoff and MacKenzie 1994, Podsakof et al. 1997, Walz and Niehoff 2000).

The greater the perceived organizational support the more the employee will feel his obligation towards the organization (Shore and Wayne 1993). When employee feels perceived organizational support from his employer, it has positive effect on his citizenship behaviors ${ }^{[38]}$ and job performance (Eisenberger et al. 1990). Having influence in policy making can also be taken as an antecedent of perceived organizational support 
(Eisenberger et al. 1986). Employees do not always perceive the existence of supportive HR practices as the organization wants them to perceive (Whitener 2001). Although, organization might encourage participation of employees in decision making but if employees perceive that organization is not willing to receive inputs from them, they will not perceive organization as supportive. Therefore employees' perception of the support that organization extends to them is expected to affect their attitude and behavior.

Allen et al. (2003) suggested that when an organization recognize employees' contribution and is eager to invest in employees that means organization is supportive and is willing to establish social exchange relationship with its employees. Allen et al. (2003) reported in their study that perceived organizational support will increase when human resource practices of the organization are perceived, by the employees, as supportive. In this scenario, employees perceive that the employer is supportive and caring. Rhoades and Eisenberger (2002) conducted meta-analysis and reported that the perceived organizational support shows medium and small size relationship with extrarole performance and other types of performance respectively. Moreover, when outliers were removed, it displayed uniform relationships with all forms of performance. They also mentioned that demographic variables like age, gender, position, tenure etc. of the employees also affect their perceived organizational support.

Research work has been done on these variables in relationship with many different variables in the context of Pakistan. Very less work has been done on job embeddedness in the context of Pakistan (Shafique et al. 2011). As far as this model is concerned, no such study similar to the application of this manuscript has been done before in Pakistan. Literature demonstrates that human resource practices have considerable impact on employee performance but the empirical studies disclose that the degree of the direct effect of these practices on employee performance is quite small. If this is the case then, it is probable that this relationship between human resource practices and employee performance is mediated by intervening variables. Therefore, it is hypothesized in this study that job embeddedness, trust and perceived organizational support are likely mediators of this relationship. Model (Figure 1) is developed for investigating the mediating effect of the above mentioned mediators, i.e. job embeddedness, perceived organizational support and trust, between HR Practices and Employee Performance (Organizational Citizenship Behavior and Task Performance).

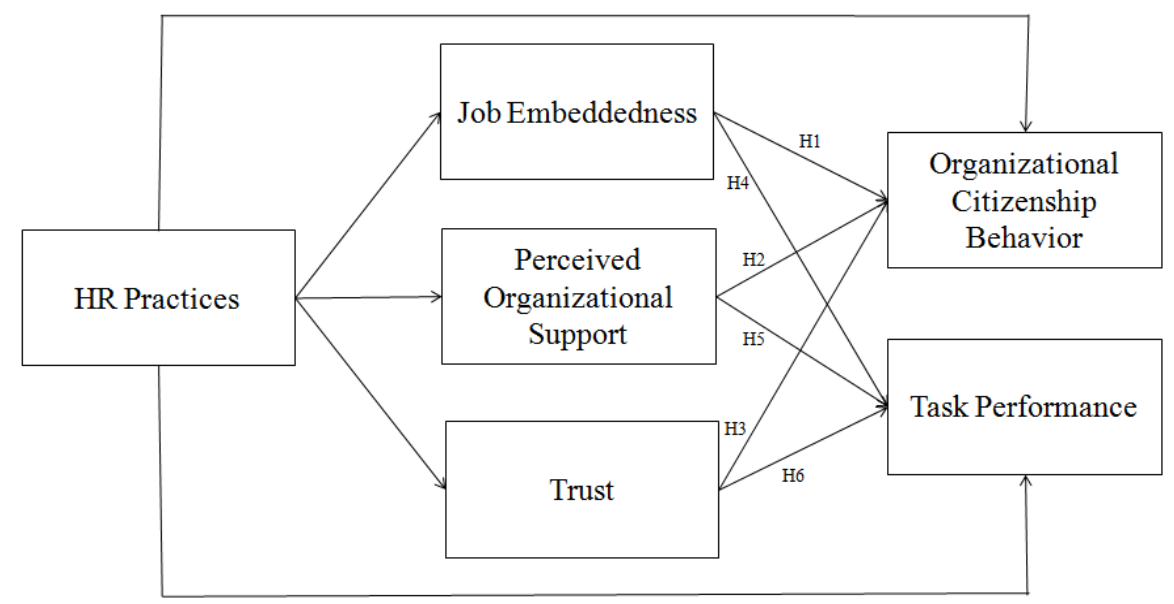

Figure 1: Theoretical Model 


\subsection{Hypotheses}

In order to test the model (Figure 1), following hypotheses have been developed.

Hypothesis 1: Job Embeddedness mediates the relationship between Human Resource Practices and Organizational Citizenship Behavior.

Hypothesis 2: $\quad$ Perceived Organizational Support mediates the relationship between Human Resource Practices and Organizational Citizenship Behavior.

Hypothesis 3: $\quad$ Trust mediates the relationship between Human Resource Practices and Organizational Citizenship Behavior.

Hypothesis 4: Job embeddedness mediates the relationship between Human Resource Practices and Task Performance.

Hypothesis 5: Perceived Organizational Support mediates the relationship between Human Resource Practices and Task Performance.

Hypothesis 6: Trust mediates the relationship between Human Resource Practices and Task Performance.

\section{Materials and methods}

This is causal study as it identifies the cause and effect relationship between different variables. In this cross sectional survey based study primary data is collected on questionnaire from one of the public sector University of Pakistan. Higher Education Commission (2002) defined Public Sector Institution as "the Institution set up by the Federal Government or a Provincial Government. Population of the study was faculty members of the mentioned university. Respondents of this data were 203 faculty members of different campuses of University. Respondents taken from different campuses of University in Islamabad, Lahore, Abbottabad, Sahiwal, Vehari, Attock and Wah were 34, 35, 34, 26, 25, 24 and 21 respectively. Purposive non-probability sampling technique is used for sampling. In this sampling technique, sample is confined to certain type of people who either have the required information or they match the criteria laid down by the researcher (Sekaran \& Bougie, 2010). As the results were supposed to be compared across gender, age, mode of employment, position, first employer and residential city of respondents, therefore almost same no. of respondents were required in each category for every variable mentioned above i.e. same no of male and female respondents for variable 'gender'.

Confirmatory Factor analysis is performed in order to find out the validity of the instrument. It is used in order to confirm the fitness of a scale used for the measurement of a variable before performing any test like regression. (Ullman \& Bentler, 2003). Age, gender and marital status, mode of employment, position, time served in current organization, time served since first job and residential city. Mode of employment is measured by taking two response choices; Contractual (1) and Permanent (2). Position is measured by 5 response choices; Professor (1), Associate Professor (2), Assistant Professor (3), Lecturer (4) and Other (5). Question posed for residential city is 'Belong to place of posting' with two response choices; Yes (1) and No (2). 
After CFA, eight items from different variables were omitted from the questionnaire which show low factor loading. Factor loading of the items is shown in Appendix A. The reliability of the questionnaire is measured through Cronbach's Alpha. Tavakol \& Dennick (2011) describe Cronbach's alpha as the most commonly used tool to measure reliability of variables. It ranges between 0 and 1. The higher the value of Cronbach's alpha, the more reliable the scale is (Santos, 1999). Collective Cronbach's alpha of all the items of questionnaire is 0.936 which is ideal. This means questionnaire is internally consistent and highly reliable. Test for reliability is also run for each variable separately. Test results as mentioned in Table 2 show the internal consistency of the scales used for different variables and values depict that the scales are also reliable separately.

\subsection{Individual characteristics}

Age, gender and marital status, mode of employment, position, time served in current organization, time served since first job and residential city. Mode of employment is measured by taking two response choices; Contractual (1) and Permanent (2). Position is measured by 5 response choices; Professor (1), Associate Professor (2), Assistant Professor (3), Lecturer (4) and Other (5). Question posed for residential city is 'Belong to place of posting' with two response choices; Yes (1) and No (2).

\subsection{Measures of variables:}

Different measures used in this study to devise the questionnaire are;

1) Human Resource Practices: Human reosurce practices are taken as independent variable. It is measured through a scale adopted from the study of Salanova et al. (2005). It consists of three dimensions namely Training, Autonomy and Technology. These dimensions are further comprise of 3 items each making it total 9 items. This scale has 5 response choices ranging from Not important (1) to Very Important (2).

2) Job Embeddedness: It is measured with the help of scale developed by Mitchell et al. (2001). After performing CFA, 1 item was removed as it has very low loading for this construct. These items were measured through 7 response choices: 'Not at all (1)' at one extreme and 'To a greater extent (7)' at the other extreme.

3) Perceived Organizational Support: It is taken as a mediator in the study. To measure Perceived organizational support, a scale with six items was used developed by Eisenberger (1986). It has 7 response choices ranging from Strongly Disagree (1) to Strongly Agree (7).

4) Trust: It is taken as another mediator for this study. To measure Trust, scale of five items was used adopted from study of Cook and Wall (1980). This scale has two dimensions namely Systems trust and Interpersonal trsut. First dimension has 7 items and second has 3 items. Likert scale with five response choices was used ranging from Stronlgy Disagree (1) to Strongly Agree (5).

5) Employee Performance: It is measured by following two dimensions.

(i) Organizational Citizenship Behavior: OCB is one of the two dependent variables. Scale for this variable is adopted from the study of Miao and Kim (2009). It consists of three dimensions and each dimension consists of three items. These three dimensions are Organizational Domain OCB, Self Domain OCB and Group Domain OCB. The nine 
items of these three dimensions are measured on likert scale with "Not at all (1)" at one extreme and "To a greater extent (7)" at other extreme.

(ii) Task Performance: It is the second dependent variable of the study. It measured by the scale adopted from the study of Welbourne et al. (1998). This scale comprise of five dimensions namely; Job, Career, Innovator, Team and Organization. All the dimensions consist of three items each. It is measured with five response choices: Needs much improvement (1), Needs some improvement (2), Satisfactory (3), Good (4), Excellent (5).

\section{Results and discussion}

SPSS and AMOS are used for the purpose of analysis. Descriptive statistics is applied on all the variables. Descriptive statistics are given in Table 1. Spearman Correlation, Multivariate Regression and tests developed by Preacher and Hayes (2004) for mediation are used to test the hypotheses.

Overall descriptive statistics of the variables are given in Table 1. Results show that respondents do think that they are provided with HR practices, with mean value of 3.55, which are facilitating for them. Mean value (3.38) for job embeddedness shows that respondents are somewhat in the middle of scale. Perceived organizational support shows similar results like job embeddedness. Mean value of 3.68 shows medium perception of support from the organization. Trust on the other hand is quite high among employees with mean value of 3.43 which shows that on the average they agree that they trust their organization. OCB shows better results with mean value of 4.39 which shows that employees are showing bit higher then medium organizational citizenship behavior. For task performance again results are in the middle of the scale with mean value of 3.33 . Table 1 shows that for all variables except job embeddedness, males have higher average than females. Although female respondents show higher job embeddedness (3.48) than males (3.35) but this difference is negligible.

Mean difference between contractual and permanent employees is somewhat mixed. Differences are not much visible. Mean difference on the basis of position shows that as the respondents move from the position of professor to the lower positions their mean value for most of the variables decreases. This displays that the more the respondent is senior in his position, the more he is embedded in his job; the more he feels perceived organizational support and trust, the higher are his performance dimensions. Mean value of all variables, except HR Practices (3.52) and OCB (4.22), is higher for those respondents for whom this organization was first employer. HR Practices (3.56) and OCB (4.45) show higher average values for those respondents whose first employer was some other organization. This difference of mean between the two groups of respondents for HR Practices is negligible. Therefore, it could be safely said that on average those employees show higher values whose first employer was this organization. For all the variables except for task performance, mean value is higher for those respondents who were residents of the city in which they were working.

In order to measure the initial relationship regarding human resource practices, job embeddedness, perceived organizational support, trust, organizational citizenship behavior and task performance of the employee Spearmen correlation (Table 2) is 
utilized. Overall mean values of variables, their standard deviations and reliability coefficients are also mention in Table 2. Human resource practices are found to be significantly positively correlated with all the variables. Job embeddedness is also significantly correlated with all the variables and this correlation is positive. Perceived organizational support is significant with all the variables except task performance $(\mathrm{b}=.088, \mathrm{p}<0.210)$. Similarly organizational citizenship behavior is found to be showing significant positive correlation all variables except task performance $(b=.004, p<0.954)$. Trust is found to be significantly correlated with all other variables except organizational citizenship behavior $(b=.118, p<0.094)$.

Correlation has found preliminary relationships but causation is still to be found. In order to investigate this causation multivariate regression (Table 3) is run taking Human resource practices independent variable and organizational citizenship behavior and task performance as dependent variables. Age, gender and marital status, mode of employment and position are also incorporated as control variables. All variables in rows are independent and all variables in columns are dependent. Unlike Linear regression, multivariate test performs an additional test to check the overall significance of the model. Table 3 contains Wilks' Lambda which tells the overall significance of the model. Values of Wilks' Lambda display that all the predictors are overall significant for the models except age and position.

Table 3 shows that results for age are significant only for organizational citizenship behavior and task performance while it is not significant for the three mediators of the study. Age has negative relationship with organizational citizenship behavior $(b=-.227)$ i.e. as age increases, organizational citizenship behavior decreases. Gender is also significant for only two dependent variables i.e. task performance $(b=-.418)$ and job embeddedness $(b=.216)$. Negative relationship with task performance shows that females are better in task performance as compare to males (this test is run for males as they were taken as 1). Marital status is significant only for organizational citizenship behavior $(b=-.343)$ with negative relationship. This shows that unmarried respondents were displaying more organizational citizenship behavior than those who were married. Mode of employment has positive relationship and is significant only for task performance $(b=-.675)$. That means contractual employees were showing better task performance as compare to permanent employees (contractual employees were taken as 1). A reason could be that contractual employees wanted to get permanent so they show better task performance while permanent employees have no such pressure so they remain work at their comfort level.

Position of the respondent is not found to be significant with any of the variable that suggests that employees do not get influenced by their position in order to judge any human resource practices provided by organization or to react to such practices. Human resource practices, as shown in Table 3, are significant with all the dependent variables with positive beta coefficients. Human resource Practices are significant with both variables of employee performance which is also consistent with previous research work (Salanova et al. 2005, Demerouti et al. 2001). Human resource practices also show highly significant positive relationship with perceived organizational support which is also proved in previous studies (Wayne et al. 1997, Eisenberger et al. 1999. This means the better the HR practices of the organization; the higher will be organizational citizenship 
behavior, task performance, job embeddedness, perceived organizational support and trust.

To find out the impact of mediator on the dependent variable, Baron and Kenny (1986) has proposed four major steps based on a procedure developed by Sobel (1982). This procedure is carried out through Sobel Test developed by Preacher and Hayes (2004). Results of this test are shown in Table 4. Results shows that c' path is insignificant (It should be insignificant in order to suggest that the relationship between independent and dependent variable is insignificant when mediator is controlled) for organizational citizenship behavior when job embeddedness (.1410) and perceived organizational support (.3357) are taken as mediators for it. Significance for indirect effect of job embeddedness and perceived organizational support shows significant results that mean full mediation exists. Therefore, job embeddedness and perceived organizational support fully mediate the relationship between human resource practices and organizational citizenship behavior which is also consistent with literature which mentions that job embeddedness (Lee et al. 2004) and perceived organizational support (Shore and Wayne 1993, Rhoades and Eisenberger 2002) increase organizational citizenship behavior. These results support Hypotheses 1 and 2.

While for trust, as mediator, results shows that its c' path is significant (.0122) and indirect effect shows p-value of 0.1656. Therefore, according to Sobel test, trust does not mediate the relationship between human resource Practices and organizational citizenship behavior. It is argued by Preacher and Hayes (2004) that P value of indirect effect does not necessarily tell the presence or absence of mediation. As path c' shows significant result but only at 0.01 while it is insignificant at 0.05 , therefore it could be said that partial mediation exists. This is also consistent with previous literature (Guest and Conway, 1999) which states that trust acts as a mediating variable between human resource practices and employee attitude. Results for trust partially supports hypothesis 3 . It is evident in the results that Job embeddedness and perceived organizational support does not mediate the relationship between HR Practices and task performance. The $p$ values for c' path is significant for both mediators (Job Emb.=.0258, POS=.0065). P values for indirect effect are insignificant which shows that no indirect effect of mediators exists for task performance. But as path c' of both mediators show $\mathrm{p}$ value which are insignificant at 0.05 and 0.01 respectively therefore partial mediation is expected to exist. Previous literature also argues that elements of job embeddedness (Sekiguchi et al. 2008) and perceived organizational support (Eisenberger et al. 1990, Rhoades and Eisenberger 2002) are expected to impact employee performance. These results partially support Hypotheses 4 and 5. Trust is showing insignificant results (.0557) for task performance in path c'. $\mathrm{P}$ value for indirect effect is also significant (.0134) which explains that significant indirect mediation exists. But indirect effect is significant at 0.05 therefore it is not full mediation rather a partial mediation exist between HR practices and task performance. This result for trust as a mediator partially supports our hypothesis 6 .

Multiple mediation tests of Preacher and Hayes (2004) is run to further cross check the mediation of three mediators for dependent variables. In this test all three mediators are put together unlike Sobel test where test is run for each mediator separately. Multiple mediation is run first for organizational citizenship behavior and then for task 
performance as dependent variables. Results for this test are shown in Table 5. For organizational citizenship behavior, path $\mathrm{c}^{\prime}$ is of prime importance. It is insignificant $(\mathrm{p}=4163)$ while model summary is depicting significant result $(\mathrm{p}=.0000)$ therefore we can say that full mediation exist for this model. Model summary result shows that this model is significant. In Table 4, Sobel test has shown that only trust was not acting as mediator for organizational citizenship behavior. But when all mediators are put together, the no mediation effect of trust is influenced by other mediators.

For task performance, model summary shows significant result $(\mathrm{p}=.000)$ which tells that the model is significant. Path $\mathrm{c}^{\prime}$ shows insignificant results $(\mathrm{p}=.0150)$ but only at 0.01 . Therefore, it can be said that partial mediation exists between human resource practices and task performance when all three mediators are taken. In Sobel test, only trust was the variable which was significant mediator for task performance. But Table 4 shows that path c' value for Job embeddedness and perceived organizational support were insignificant only at 0.01 and therefore, there were chances of partial mediation. When all the mediators are put together, these chances enhanced and show partial mediation of all the variables together.

\section{Conclusion}

Confirmatory factor analysis shows that the scale used for the variables of the study are valid in the Higher Education sector of Pakistan. Male respondents are shown to have higher mean values for almost all the variable. Age, gender, marital status, position in the organization and mode of employment were control variables. Multivariate regression analysis gives evidence that these variables do not affect dependent variable to a greater extent. Few of them are found to be significant with few variables but on the average they do not cast visible impact.

Almost all the variables of the study show positive correlation with each other. This shows that there exists correlation between them. It can be said that all three variables do affect dependent variables as mediators. Sobel test (Table 4) shows some mediators as insignificant but Multiple Mediation shows that when mediators work together they all become active and show full or partial mediation. Another argument for this could be that, practically, when organizations are working there is no such working environment where only a single mediator affects the employees separately. Mediators work together and affect each other's effect. Results shows that job embeddedness, perceived organizational support and trust do mediate the relationship between HR practices and employees' performance.

\section{Limitations of the study}

A considerable limitation is the cross-sectional design of the study which does not allow us to make generalized inference about the causality path. This limitation is also identified in many other studies conducted for different variables. Therefore future research should be carried out with longitudinal design and in other sectors as well.

Different campuses of one university, existing in different cities of Pakistan, are taken as population which limits the possibility of generalizing the results. Relationships between 
variables may differ if data is collected from other industries and countries. Some of the results in this study are contradictory with literature which might be due to the reason that there exist many factors which affect performance of an employee such as personality, religion and environment which are not taken into consideration in this study.

\section{References}

1. Allen, D. G., Shore, L. M. and Griffeth, R. W. (2003). The role of perceived organizational support and supportive human resource practices in the turnover process. Journal of management, 29(1), 99-118.

2. Baron, R. M., and Kenny, D. A. (1986). The moderator-mediator variable distinction in social psychological research: Conceptual, strategic, and statistical considerations. Journal of personality and social psychology, 51(6), 1173.

3. Bennis, W.G. and Nanus, B. (1985). Leaders: The Strategy for Taking Charge. New York: Harper \& Row.

4. Bergiel, E. B., Nguyen, V. Q., Clenney, B. F. and Taylor, G. S. (2009). Human resource practices, job embeddedness and intention to quit. Management Research News, 32(3), 205-219.

5. Blau, P. M. (1964). Exchange and power in social life. New York: Wiley.

6. Cook, J. and Wall, T. (1980). New Work Attitude Measures of Trust, Organisational Commitment and Personal Need Non-fulfilment. Journal of Occupational Psychology, 53, 39-52.

7. Culbert, S. A. and McDonough, J. J. (1986). The Politics of Trust and Organizational Empowerment. Public Administration Quarterly, 10: 171-88.

8. Cunningham, G. B., Fink, J. S. and Saga, M. (2005). Extension and Further Examination of the Job Embeddedness Construct. J. Sports Manage, 19(3), 319335.

9. Demerouti E., Bakker, A. B., Nachreiner, F. and Schaufeli, W. B. (2001). The Job Demands - Resources model of burnout. Journal of Applied Psychology, 86, 499512.

10. Diffie-Couch, P. (1984). Building a Feeling of Trust in the Company. Supervisory Management, 3, 136.

11. Eisenberger, R., Fasolo, P. and Davis-LaMastro, V. (1990). Perceived organizational support and employee diligence, commitment, and innovation. Journal of applied psychology, 75(1), 51.

12. Eisenberger, R., Huntington, R., Hutchison, S. and Sowa, D. (1986). Perceived organizational support. Journal of Applied Psychology, 71: 500-507.

13. Eisenberger, R., Rhoades, L. and Cameron, J. (1999). Does pay for performance increase or decrease perceived self-determination and intrinsic motivation? Journal of Personality and Social Psychology, 77, 1026 -1040.

14. Gibb, J. (1964). Climate for Trust Formation. In Bradford, L., Gibb, J. and Benne, K. (eds) T-group Therapy and Laboratory Method, New York: Wiley.

15. Gould-Williams, J. (2003). The importance of HR practices and workplace trust in achieving superior performance: a study of public-sector organizations. International Journal of Human Resource Management, 14(1), 28-54. 
16. Gouldner, A. W. (1960). The norm of reciprocity: A preliminary statement. American Sociological Review, 25,161-178.

17. Guest, D. and Conway, N. (1999). Peering into the Black Hole: The Downside of the New Employment Relations in the UK. British Journal of Industrial Relations, 37(3): 367-89.

18. Guzzo, R. A. and Noonan, K. A. (1994). Human Resource Practices as Communications and the Psychological Contract. Human Resource Management, 33, 447-62.

19. Hackman, J. R., and Oldham, G. R. (1980). Work redesign. Reading, MA: Addison-Wesley.

20. Hage, J. (1980). Theories of Organisations: Forms, Process and Transformation. New York: Wiley.

21. Härtel, C. E. J. (2008). How to build a healthy emotional culture and avoid a toxic culture. In C. L. Cooper and N. M. Ashkanasy (Eds.), Research companion to emotion in organizations (pp. 575-588). Cheltenham, UK: Edwin Elgar.

22. Higher Education Commission (2002). Higher Education Commission Ordinance 2002. Islamabad, Pakistan. Retrieved from http://www.hec.gov.pk/MediaPublication/HECPublication/Documents/455_HEC Ordinance.pdf

23. Holtom, B. C. and O' Neill, B. S. (2004). Job Embeddedness: A theoretical foundation for developing a comprehensive nurse retention plan. J. Nurs. Adm., 34(5), 216-227.

24. Iles, P., Mabey, C. and Robertson, I. (1990). HRM Practices and Employee Commitment: Possibilities, Pitfalls and Paradoxes. British Journal of Management, 1: 147-57.

25. Kuenzi, M., and Schminke, M. (2009). Assembling fragments into a lens: A review, critique, and proposed research agenda for the organizational work climate literature. Journal of Management, 35, 634-717.

26. Lee, T. W., Mitchell, T. R., Sablynski, C. J., Burton, J. P., and Holtom, B. C. (2004). The effects of job embeddedness on organizational citizenship, job performance, volitional absences, and voluntary turnover. Academy of Management Journal, 47(5), 711-722.

27. Luhmann, N. (1979) Trust and Power. Chichester: Wiley.

28. Miao, R. T., and Kim, H. G. (2009). Gender as a moderator of the relationship between organizational citizenship behaviors and team effectiveness in China. Asian Social Science, 5(10), P98.

29. Mitchell, T. R., Holtom, B. C., Lee, T. W., Sablynski, C. J., and Erez, M. (2001). Why people stay: Using job embeddedness to predict voluntary turnover. Academy of management journal, 44(6), 1102-1121.

30. Motowildo, S. J., Borman, W. C., and Schmit, M. J. (1997). A theory of individual differences in task and contextual performance. Human performance, 10(2), 71-83.

31. Organ, D. W. (1988). Organizational citizenship behavior: The good soldier syndrome. Lexington Books/DC Heath and Com. 
32. Organ D. W. (1997). Organizational citizenship behavior: It's construct clean-up time. Human Performance, 10, 85-97.

33. Pascale, R.T. and Athos, A.G. (1981). The Art of Japanese Management. New York: Warner Books.

34. Podsakoff, P. M., Ahearne, M. and MacKenzie, S. B. (1997). Organizational citizenship behavior and the quantity and quality of work group performance. Journal of Applied Psychology, 82(2): 262-70.

35. Podsakoff, P. M. and MacKenzie, S. B. (1994). Organizational citizenship behaviors and sales unit effectiveness. Journal of Marketing Research, 31(3): 35163.

36. Preacher, K. J. and Hayes, A. F. (2004). SPSS and SAS procedures for estimating indirect effects in simple mediation models. Behavior Research Methods, Instruments, \& Computers, 36(4), 717-731.

37. Rhoades, L. and Eisenberger, R. (2002). Perceived organizational support: a review of the literature. Journal of applied psychology, 87(4), 698.

38. Robinson, S. L., Kraatz, M. S. and Rousseau, D. M. (1994). Changing obligations and the psychological contract: A longitudinal study. Academy of Management Journal, 37, 137-152.

39. Rousseau, D. M. (1989). Psychological and Implied Contracts in Organizations. Employee Responsibility and Rights Journal, 2, 121-39.

40. Salanova, M., Agut, S. and Peiró, J. M. (2005). Linking organizational resources and work engagement to employee performance and customer loyalty: the mediation of service climate. Journal of applied Psychology, 90(6), 1217.

41. Santos, J. R. A. (1999). Cronbach's alpha: A tool for assessing the reliability of scales. Journal of extension, 37(2), 1-5.

42. Schaufeli, W. B. and Bakker, A. B. (2004). Job demands, job resources, and their relationship with burnout and engagement: A multi-sample study. Journal of Organizational Behavior, 25, 293-315.

43. Schneider, B. (2000). The psychology of organizations. In N. M. Ashkanasy, C. Wilderom, \& M. F. Peterson (Eds.), Handbook of Organizational culture and climate (pp. xvii-xxi). Thousand Oaks, CA: Sage.

44. Schneider, B., White, S. S. and Paul, M. C. (1998). Linking service climate and customer perceptions of service quality: Test of a causal model. Journal of Applied Psychology, 83, 150 -163.

45. Sekiguchi, T., Burton, J. P. and Sablynski, C. J. (2008). The role of job embeddedness on employee performance: the interactive effects with leadermember exchange and organization-based self-esteem. Personnel Psychology, 61(4), 761-792.

46. Shafique, M., Qadeer, F., Ahmad, M. and Rehman, R. (2011). Impact of job embeddedness on leave intention: An understanding from higher education (HE) system. African Journal of Business Management, 5(30), 11794-11801

47. Shaw, J. D., Delery, J. E., Jenkins, G. D. and Gupta, N. (1998). An organizationlevel analysis of voluntary and involuntary turnover. Academy of Management Journal, 41, 511-525. 
48. Shore, L. M. and Wayne, S. J. (1993). Commitment and employee behavior: Comparison of affective commitment and continuance commitment with perceived organizational support. Journal of Applied Psychology, 78: 774-780.

49. Sobel, M. E. (1982). Asymptotic confidence intervals for indirect ef-fects in structural equation models. In S. Leinhart (Ed.), Sociologi-cal methodology 1982 (pp. 290-312). San Francisco: Jossey-Bass

50. Tavakol, M., \& Dennick, R. (2011). Making sense of Cronbach's alpha. International journal of medical education, 2, 53.

51. Ullman, J. B., \& Bentler, P. M. (2003). Structural equation modeling. John Wiley \& Sons, Inc.

52. Van Dyne, L., Cummings, L. L. and McLean-Parks, J. (1995). Extra-role behaviors: In pursuit of construct and definitional clarity (a bridge over muddied waters). In Cummings LL, Staw BM (Eds.), Research in organizational behavior (Vol. 17, pp. 215-285). Greenwich, CT: JAI.

53. Walz, S. M. and Niehoff, B. P. (2000). Organizational citizenship behaviors: Their relationship to organizational effectiveness. Journal of Hospitality and Tourism Research, 24(3): 108-26

54. Wayne, S. J., Shore, L. M. and Liden, R. C. (1997). Perceived organizational support and leader-member exchange: A social exchange perspective. Academy of Management Journal, 40, 82-111.

55. Welbourne, T. M., Johnson, D. E. and Erez, A. (1998). The role-based performance scale: Validity analysis of a theory-based measure. Academy of management journal, 41(5), 540-555.

56. Whitener, E. M. (2001). Do 'high commitment' human resource practices affect employee commitment? A cross level analysis using hierarchical linear modeling. Journal of Management, 27: 515-536. 
Table 1: Descriptive analysis (Mean) of respondents

\begin{tabular}{|c|c|c|c|c|c|c|c|c|c|c|c|c|c|c|}
\hline & \multirow[t]{2}{*}{$\begin{array}{c}\text { Over } \\
\text { all }\end{array}$} & \multicolumn{2}{|c|}{ Gender } & \multicolumn{2}{|c|}{ Mode of employment } & \multicolumn{5}{|c|}{ Position } & \multicolumn{2}{|c|}{$\begin{array}{c}\text { First } \\
\text { employer }\end{array}$} & \multicolumn{2}{|c|}{$\begin{array}{c}\text { Residential } \\
\text { City }\end{array}$} \\
\hline & & Male & Female & Contractual & Permanent & Prof. & $\begin{array}{l}\text { Assoct. } \\
\text { Prof. }\end{array}$ & $\begin{array}{c}\text { Assist. } \\
\text { Prof. }\end{array}$ & Lecturer & Other & Yes & No & Yes & No \\
\hline $\begin{array}{l}\text { HR } \\
\text { Pract. }\end{array}$ & 3.55 & 3.60 & 3.40 & 3.44 & 3.58 & 4.00 & 4.00 & 3.46 & 3.58 & 3.59 & 3.52 & 3.56 & 3.63 & 3.46 \\
\hline $\begin{array}{l}\text { Job } \\
\text { Emb. }\end{array}$ & 3.38 & 3.35 & 3.48 & 3.47 & 3.36 & 4.00 & 3.67 & 3.15 & 3.56 & 3.24 & 3.67 & 3.28 & 3.54 & 3.20 \\
\hline POS & 3.68 & 3.69 & 3.66 & 3.79 & 3.65 & 4.00 & 4.00 & 3.52 & 3.75 & 3.76 & 3.87 & 3.61 & 3.75 & 3.60 \\
\hline Trust & 3.43 & 3.46 & 3.34 & 3.30 & 3.46 & 4.00 & 4.00 & 3.23 & 3.57 & 3.34 & 3.63 & 3.36 & 3.45 & 3.40 \\
\hline OCB & 4.39 & 4.41 & 4.32 & 4.47 & 4.37 & 4.67 & 4.00 & 4.41 & 4.36 & 4.45 & 4.22 & 4.45 & 4.42 & 4.36 \\
\hline $\begin{array}{l}\text { Task } \\
\text { Perf. }\end{array}$ & 3.33 & 3.44 & 3.00 & 2.77 & 3.49 & 4.00 & 4.00 & 3.25 & 3.43 & 3.07 & 3.39 & 3.32 & 3.19 & 3.49 \\
\hline
\end{tabular}

Table 2: Spearman Correlation

\begin{tabular}{lcccccc}
\hline & HRP & JOB.EMB & POS & TRUST & OCB & TASK.PERF \\
\hline HRP & 1.000 & & & & & \\
JOB.EMB & $.307^{* *}$ & 1.000 & & & & \\
POS & $.247^{* *}$ & $.444^{* *}$ & 1.000 & & & \\
TRUST & $.210^{* *}$ & $.467^{* *}$ & $.547^{* *}$ & 1.000 & & \\
OCB & $.156^{*}$ & $.178^{*}$ & $.331^{* *}$ & .118 & 1.000 & \\
TASK.PERF & $.173^{*}$ & $.179^{*}$ & .088 & $.360^{* *}$ & .004 & 1.000 \\
\hline Mean & 3.55 & 3.38 & 3.68 & 3.43 & 4.39 & 3.33 \\
Stand. Deviation & .690 & .738 & .739 & .717 & .752 & .899 \\
Reliability Coeff. & .744 & .930 & .786 & .742 & .879 & .931 \\
\hline **. Correlation is significant at the 0.01 level (2-tailed). & & \\
*. Correlation is significant at the 0.05 level (2-tailed). & & \\
\hline
\end{tabular}


Table 3: Multivariate Regression analysis

\begin{tabular}{lccccc}
\hline & OCB & Task Perf. & Job Emb. & POS & Trust \\
\hline Intercept & 4.447 & 1.646 & 2.299 & 2.968 & 2.507 \\
Age & $-.227^{*}$ & $.221^{*}$ & -.115 & -.167 & -.020 \\
Gender & -.012 & $-.418^{* * *}$ & $.216^{*}$ & -.020 & -.116 \\
Marital Status & $-.343^{* * *}$ & .086 & -.048 & .154 & .083 \\
Mode of employment & -.046 & $.675^{* * *}$ & -.149 & -.185 & .127 \\
Position & .015 & .008 & -.022 & -.025 & .012 \\
HRP & $.212 * * *$ & $.159 *$ & $.388^{* * *}$ & $.328 * * *$ & $.199 * * *$ \\
\hline
\end{tabular}

\begin{tabular}{lccc} 
Overall significance of Multivariate Regression models (Wilks' Lambda) & \\
\hline Effect & Value & F & Sig. \\
\hline Intercept & .649 & $20.794^{\mathrm{b}}$ & .000 \\
Age & .962 & $1.504^{\mathrm{b}}$ & .190 \\
Gender & .927 & $3.038^{\mathrm{b}}$ & .012 \\
Marital Status & .921 & $3.289^{\mathrm{b}}$ & .007 \\
Mode of employment & .876 & $5.454^{\mathrm{b}}$ & .000 \\
Position & .998 & $.090^{\mathrm{b}}$ & .994 \\
HRP & .855 & $6.489^{\mathrm{b}}$ & .000 \\
\hline *. Correlation is significant at the 0.1 level (2-tailed). & & \\
**. Correlation is significant at the 0.05 level (2-tailed). \\
***. Correlation is significant at the 0.01 level (2-tailed).
\end{tabular}


Table 4: Sobel Test

\begin{tabular}{|c|c|c|c|c|c|c|c|c|c|c|c|c|}
\hline \multirow{3}{*}{$\begin{array}{l}\text { Dependent } \\
\text { Variable }\end{array}$} & \multicolumn{6}{|c|}{ Organizational Citizenship Behavior } & \multicolumn{6}{|c|}{ Task Performance } \\
\hline & \multicolumn{2}{|c|}{ Job Emb. } & \multicolumn{2}{|c|}{ POS } & \multicolumn{2}{|c|}{ Trust } & \multicolumn{2}{|c|}{ Job Emb. } & \multicolumn{2}{|c|}{ POS } & \multicolumn{2}{|c|}{ Trust } \\
\hline & Coeff. & $\begin{array}{c}\text { Sig } \\
\text { (two) }\end{array}$ & Coeff. & $\begin{array}{c}\text { Sig } \\
\text { (two) }\end{array}$ & Coeff. & 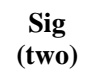 & Coeff. & $\begin{array}{c}\text { Sig } \\
\text { (two) }\end{array}$ & Coeff. & $\begin{array}{c}\text { Sig } \\
\text { (two) }\end{array}$ & Coeff. & $\begin{array}{c}\text { Sig } \\
\text { (two) }\end{array}$ \\
\hline $\mathbf{c}(\mathbf{Y X})$ & .1914 & .0122 & .1914 & .0122 & .1914 & .0042 & .2545 & .0052 & .2545 & .0052 & .2545 & .0052 \\
\hline $\mathbf{a}(\mathbf{M X})$ & .3484 & .0000 & .2896 & .0001 & .2079 & .0964 & .3484 & .0000 & .2896 & .0001 & .2079 & .0042 \\
\hline b(YM.X) & .2196 & .0016 & .4207 & .0000 & .1657 & .0324 & . 1220. & . 1443 & -.0129 & .8832 & .4195 & .0000 \\
\hline $\mathbf{c}^{\prime}(\mathbf{Y X} . \mathbf{M})$ & .1149 & .1410 & .0696 & .3357 & .1237 & .0122 & .2120 & .0258 & .2582 & .0065 & .1673 & .0557 \\
\hline $\begin{array}{l}\text { Indirect } \\
\text { Effect }\end{array}$ & & .0098 & & .0009 & & .1656 & & .1717 & & .8866 & & .0134 \\
\hline
\end{tabular}

Independent variable - HR Practices

Table 5: Multiple Mediation

\begin{tabular}{l|lll|lll}
\hline & \multicolumn{3}{|c}{ Organizational Citizenship } & \multicolumn{3}{c}{ Task Performance } \\
& Variables & Coeff. & P & Variables & Coeff. & P \\
\hline Path a & JOB.EMB & .3484 & .0000 & JOB.EMB & .3484 & .0000 \\
& POS & .2896 & .0001 & POS & .2896 & .0001 \\
& TRUST & .2079 & .0042 & TRUST & .2079 & .0042 \\
\hline Path b & JOB.EMB & -.1499 & .2268 & JOB.EMB & .0229 & .7977 \\
& POS & .0895 & .0000 & POS & -.3067 & .0020 \\
\hline Path c & TRUST & .4546 & .0677 & TRUST & .5665 & .0000 \\
\hline Path c' & HRP & .1914 & .0122 & HRP & .2545 & .0052 \\
\hline $\begin{array}{l}\text { Model } \\
\text { Summary }\end{array}$ & & .0598 & .4163 & HRP & .2176 & .0150 \\
\hline Independent variable - HR Practices & & .0000 & & & .0000 \\
\hline
\end{tabular}


Appendix

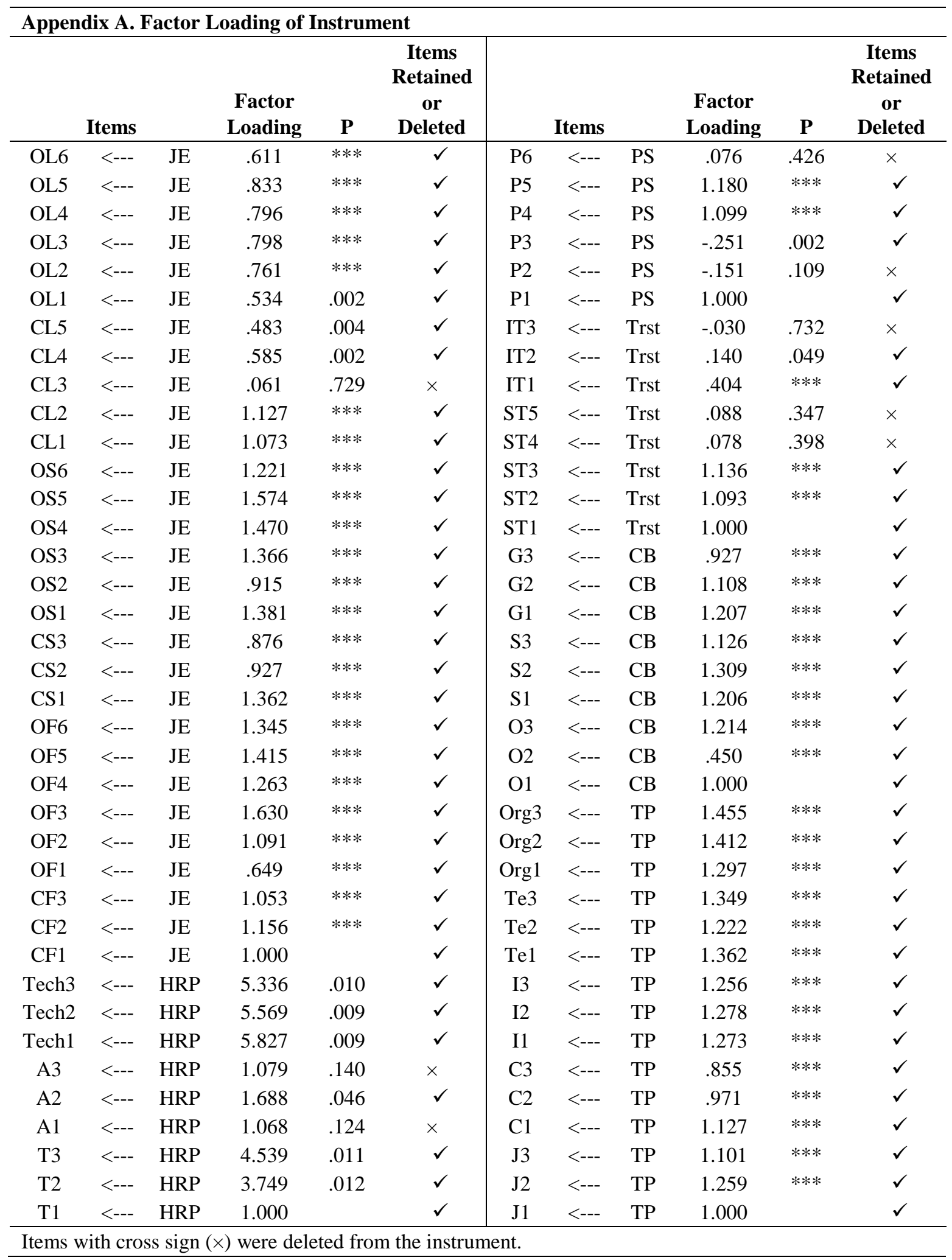

